\title{
Breast cancer patients' recall of receiving patient assistance services
}

\author{
Jenny J Lin ${ }^{1 *}$, Kezhen Fei ${ }^{2}$, Rebeca Franco ${ }^{2}$ and Nina A Bickell ${ }^{1,2}$
}

\begin{abstract}
Background: The objective of this study was to assess factors that affect breast cancer patients' recall of patient assistance services.

Methods: We surveyed newly-diagnosed breast cancer patients and compared recall of receiving patient assistance services at 2 weeks and 6 months in a patient-assistance randomized controlled trial aimed to connect women to such programs. The intervention group received information about assistance programs targeted to their practical, psychosocial, and/or informational needs; the control group received a Department of Health pamphlet about breast cancer and its treatment, including a list of patient assistance services.
\end{abstract}

Findings: Of 333 women, 210 (63\%) reported informational, 183 (55\%) psychosocial and 177 (53\%) practical needs. At 2 weeks, 96\% (202/210) of women with informational needs reported receiving informational material but at 6 months, recall dropped to 69\% (140/210). All women whose informational needs were met recalled receiving information, compared to $31 \%$ whose needs were unmet $(p<0.0001)$. Of 109 intervention patients with psychosocial or practical needs, $77 \%$ (79) contacted a program specified in their action plan at 2 weeks. However, at 6 months, only 39\% (31/79) recalled contacting a program. Women without recall were less likely to report having their needs met ( $6 \%$ vs. $58 \% ; p<0.001)$.

Conclusions: Recall of patient assistance services is strongly related to having needs met. Use of patient surveys to evaluate utilization or impact of such programs should be used with caution due to poor patient recall.

Clinical Trials \# NCT00233077: http://www.clinicaltrials.gov/ct2/show/NCT00233077?term=Nina+Bickell\&rank=2

Keywords: Recall, Survey research, Breast cancer, Patient assistance

\section{Introduction}

Since medical chart review is time-consuming, costly and logistically challenging in a decentralized health system, patient self-report via questionnaire surveys are often used to assess utilization of services or treatments (Gordon et al. 1993; Paskett et al. 1996). Some studies show patient self-report to be relatively accurate for cancer screening procedures such as pap smears, mammograms and fecal occult blood testing (Gordon et al. 1993; Zapka et al. 1996; Mandelson et al. 1999), cancer treatment (Maunsell et al. 2005; Clegg et al. 2001; Oberst et al. 2009; Liu et al. 2010; Phillips et al. 2005; Schootman et al. 2005), and medication therapy (Boudreau

\footnotetext{
* Correspondence: jenny.lin@mssm.edu

${ }^{1}$ Division of General Internal Medicine, Mount Sinai School of Medicine, One Gustave L. Levy Place, Box 1087, New York, NY 10029, USA

Full list of author information is available at the end of the article
}

et al. 2004; Paganini-Hill \& Clark 2007; Caskie \& Willis 2004). However, potential problems with patient selfreport include inaccurate recall of timing or frequency of screening tests (Bancej et al. 2004; Caplan et al. 2003a; Caplan et al. 2003b; Ferrante et al. 2008; Howard et al. 2009) or of details of treatment duration or type (Clegg et al. 2001; Paganini-Hill \& Clark 2007). Furthermore, some studies show that cancer survivors may not accurately recall details about their stage of disease, type of tumor, chemotherapy regimens or even having had the disease (Nissen \& Tsai 2011; Desai et al. 2001). Accuracy of self-report also appears to decrease with the passage of time (Boudreau et al. 2004; Craig et al. 2009).

Efficacy of patient assistance programs, educational or psychosocial interventions is often evaluated, at least in part, by questionnaires (Fiscella et al. 2011; Freund et al. 2008; David et al. 2011; Allicock et al. 2010). These surveys 
often ask participants to rate satisfaction with, utilization of or effectiveness of program services. As participants may have inaccurate recollections of their use of such programs and interventions, it is important to assess factors that affect patient recall. Accurate recall becomes particularly important if future funding decisions are based in part on patients' recall of service utilization. Moreover, as many studies evaluating health care utilization are based on survey data, it is important to assess the reliability of selfreported data collected by survey questionnaire. This study was part of a randomized controlled trial to evaluate whether connecting women with newly-diagnosed breast cancer with patient-assistance services could improve use of adjuvant therapies. In this paper, we evaluate newlydiagnosed breast cancer patients' recall of informational materials received and patient assistance programs contacted.

\section{Methods}

\section{Setting and participants}

Women with early-stage breast cancer who were eligible for post-surgical adjuvant therapy were recruited from 8 New York City hospitals (4 municipal, 4 tertiary referral centers). Women were recruited within 2-4 weeks after definitive surgical treatment and were block-randomized to intervention or usual care. Women who did not speak English or Spanish or could not provide informed consent were excluded. The study was approved by the IRBs of all 8 participating hospitals.

\section{Study design \& intervention}

We surveyed participants at baseline and 6 months about their experiences with care, health status, social support, self-efficacy, knowledge, attitudes and beliefs about breast cancer and its treatment, patient assistance programs contacted and help received from programs. Scales for health status (SF-12), social support (Strogatz et al. 1997), and medical mistrust (LaVeist et al. 2000) were scored to 100 with higher values indicating higher health status, social support, and physician trust, respectively. For all patients, we conducted a baseline survey measuring breast cancer experiences, knowledge, attitudes and beliefs, and a needs assessment. For intervention patients, we identified 3 high-quality patient assistance programs that could address each patient's identified need and created an individualized action plan with each patient to enable contact with the patient assistance programs. A hard copy of the action plan and related print materials were mailed. Patients in the control group were sent a pamphlet about breast cancer and its treatment created by the New York State Department of Health that also included resources' contact information. Two weeks later, we called all patients to confirm receipt of mailed materials; intervention patients were also asked whether they had connected with the programs specified in their action plan. If they did not connect with a patient assistance program and still had psychosocial or practical needs, we assigned an outreach worker to help them connect with a program. At 6 months, we surveyed patients to determine the type of help they had received from the patient assistance program and how helpful it was. A patient was classified as having gotten her needs met if she reported receiving information, counseling or practical help for her identified need.

\section{Analysis}

Summary statistics were used to describe baseline demographics, and chi-square tests for categorical variables, T-tests or ANOVA for continuous variables to assess group differences. Logistic regression models were fit to assess risk factors of the primary outcome, 6-month recall of patient assistance services. All analyses were performed using SAS version 9.2, with the type 1 error rate fixed at 0.05 (2 tailed).

\section{Results}

Of the 333 women who completed the 6 month followup survey, 210 (63\%) reported informational needs. At 2 weeks, 96\% (202/210) reported receiving the breast cancer information pamphlet but at 6 months, only $69 \%$ $(140 / 210)$ recalled receiving informational material (Table 1). Of the 140 who recalled getting informational material, $80 \%$ reported they had their informational needs met. All 112 women who had their informational needs met recalled getting informational material (100\%; $\mathrm{p}<0.001$ ), compared to $31 \%$ of those who did not have their informational needs met. Of the 109 women in the intervention group with psychosocial or practical needs who were told of relevant assistance programs, 79 (77\%) contacted the patient assistance program specified in their action plan at 2 weeks. However, at 6 months, only 31/79 (39\%) recalled contacting a program. Women who did not recall contacting a program at 6 months were less likely to have had their psychosocial or practical needs met $(6 \%$ vs. 58\%; p < 0.001). Age, income, race, education, language spoken, social support, adjuvant treatment, trust in physicians and physical or emotional health status did not affect either recall of informational material or programs contacted.

In multivariable analysis adjusting for age, education and receipt of chemotherapy, women who had their psychosocial or practical needs met were almost 4 times more likely (95\% confidence interval: 2.35 - 6.55) to recall having contacted a patient assistance program compared to women who did not have their needs met (Table 2). 
Table 1 Factors associated with recall among women with informational needs \& women with practical or psychosocial needs

\begin{tabular}{|c|c|c|c|c|c|c|}
\hline & $\begin{array}{c}\text { Recalled } \\
\text { Informational } \\
\text { help }(N=140)\end{array}$ & $\begin{array}{l}\text { Did not recall } \\
\text { Informational } \\
\text { Help }(N=62)\end{array}$ & $\mathbf{P}$ & $\begin{array}{c}\text { Recalled } \\
\text { Practical or } \\
\text { Psychosocial } \\
\text { Help }(\mathrm{N}=31)\end{array}$ & $\begin{array}{l}\text { Did not recall } \\
\text { Practical or } \\
\text { Psychosocial } \\
\text { help }(\mathrm{N}=48)\end{array}$ & $\mathbf{P}$ \\
\hline Age (yrs) mean $\pm S D$ & $57 \pm 11.9$ & $58 \pm 10.0$ & 0.62 & $56 \pm 10.6$ & $56 \pm 12.1$ & 0.78 \\
\hline Race & & & 0.35 & & & 0.49 \\
\hline Black & $30(22 \%)$ & $19(32 \%)$ & & $7(24 \%)$ & $14(30 \%)$ & \\
\hline White & $45(34 \%)$ & $18(31 \%)$ & & $9(31 \%)$ & $9(19 \%)$ & \\
\hline Hispanic & $59(44 \%)$ & $22(37 \%)$ & & $13(45 \%)$ & $24(51 \%)$ & \\
\hline High school graduate & $102(73 \%)$ & $45(73 \%)$ & 0.97 & $20(65 \%)$ & $34(71 \%)$ & 0.56 \\
\hline Insurance & & & 0.36 & & & 0.78 \\
\hline Medicare & $21(15 \%)$ & $13(21 \%)$ & & $4(13 \%)$ & $9(19 \%)$ & \\
\hline Medicaid/Non-Insured & $51(36 \%)$ & $17(27 \%)$ & & $14(45 \%)$ & $21(44 \%)$ & \\
\hline Commercial & $68(49 \%)$ & $32(52 \%)$ & & $13(42 \%)$ & $18(38 \%)$ & \\
\hline Income $<\$ 15,000 /$ year & $46(33 \%)$ & $19(31 \%)$ & 0.76 & $11(35 \%)$ & $17(35 \%)$ & 0.99 \\
\hline English speaking & $81(58 \%)$ & 39 (63\%) & 0.50 & $18(58 \%)$ & $22(46 \%)$ & 0.29 \\
\hline Needs met & $112(80 \%)$ & 0 & $<0.001^{*}$ & $18(58 \%)$ & $3(6 \%)$ & $<0.001^{*}$ \\
\hline Radiation treatment received & $93(67 \%)$ & $45(73 \%)$ & 0.42 & $21(68 \%)$ & $34(71 \%)$ & 0.77 \\
\hline Chemotherapy received & $88(63 \%)$ & $34(56 \%)$ & 0.31 & $20(65 \%)$ & $30(63 \%)$ & 0.86 \\
\hline Hormonal therapy received & $99(71 \%)$ & $48(79 \%)$ & 0.27 & $24(77 \%)$ & $34(71 \%)$ & 0.52 \\
\hline Trust $M D$, mean $\pm \mathrm{SD}^{+}$ & $94 \pm 8.4$ & $92 \pm 8.2$ & 0.07 & $93 \pm 9.1$ & $92 \pm 9.7$ & 0.68 \\
\hline Instrumental Social Support, mean $\pm \mathrm{SD}^{+}$ & $67 \pm 27.3$ & $70 \pm 24.4$ & 0.48 & $71 \pm 29.5$ & $67 \pm 25.2$ & 0.50 \\
\hline Emotional Social Support, mean $\pm \mathrm{SD}^{+}$ & $79 \pm 19.3$ & $79 \pm 18.8$ & 0.83 & $77 \pm 21.2$ & $78 \pm 19.6$ & 0.91 \\
\hline SF-12, Physical Health, mean \pm SD $^{+}$ & $44 \pm 11.7$ & $46 \pm 10.3$ & 0.20 & $45 \pm 9.0$ & $44 \pm 11.4$ & 0.53 \\
\hline SF-12, Mental Health, mean \pm SD $^{+}$ & $49 \pm 11.4$ & $46 \pm 10.1$ & 0.08 & $48 \pm 13.4$ & $48 \pm 12.4$ & 0.93 \\
\hline
\end{tabular}

${ }^{+}$Scores scaled to 100 .

\section{Discussion}

Surveys are widely used to assess patients' experiences, beliefs and knowledge about medical care and treatment. While surveys are an efficient method to collect data, they may not always be accurate or reliable. We found that breast cancer patients' recall of information about patient assistance programs was not associated with an individual patient's psychological or physical state but rather on the direct relevance and impact of the data and programs on their lives. Nearly all of the women who received informational materials about breast cancer and treatment recalled getting this information at 2 weeks, but this proportion dropped substantially by 6 months.

Table 2 Multivariable model predicting recall of practical and psychosocial help

\begin{tabular}{llc}
\hline Covariates & $\begin{array}{l}\text { RR (95\% Confidence } \\
\text { Interval) }\end{array}$ & P \\
\hline Age & $1.00(0.98-1.03)$ & 0.65 \\
\hline High school education & $0.88(0.56-1.38)$ & 0.57 \\
\hline Chemotherapy received & $1.23(0.75-2.02)$ & 0.41 \\
\hline Practical/psychosocial needs met & $3.93(2.36-6.55)$ & $<0.001$ \\
\hline Model c-statistics $=0.778 ; p<0.001$. & &
\end{tabular}

Strikingly, their recall of having received informational material was significantly associated with whether they reported that their informational needs had been met.

Even more striking was the poor recall of practical and psychosocial services in our study. Of the women with underlying psychosocial or practical needs, more than three-quarters report contacting patient assistance programs initially, but by 6 months, only a third of the women who had contacted a program recalled doing so. Similar to recall of informational material, recall of contacting a program was also strongly related to whether women felt their needs had been met.

Patients who have better recall report more satisfaction with physician communication (Gabrijel et al. 2008) and greater trust of their providers (Posma et al. 2009). Additionally, patients' accurate recall of medical information can directly affect adherence with prescribed treatment regimens (Kessels 2003; Watson \& McKinstry 2009; Pickney \& Arnason 2005) and can indirectly provide signals about patients' experiences and the quality of those experiences. Moreover, recall of services utilized may impact patients' reported satisfaction and thus affect quality improvement efforts and possibly reimbursements tied 
to quality ratings (van Campen et al. 1995; Kravitz 1998; Turnbull \& Luther 1996; Epstein et al. 2004; Takach 2011; Bickell 2999) From a research perspective, asking patients about services utilized offers a less expensive assessment approach than conducting chart reviews, particularly for care that may be fragmented and not accessible electronically. Studies find patient report to be reliable for cancer treatments received (Oberst et al. 2009; Phillips et al. 2005; Schootman et al. 2005; Penfold et al. 2011), yet the reliability of patient report to assess utilization is variable (Lubeck \& Hubert 2005) with greater concerns among vulnerable patients (Sohler et al. 2009). Our study calls into question the accuracy of self-reported utilization of patient assistance services among breast cancer patients. Any inferences made about underutilization of services reported in survey data using patient self-report should be treated with caution.

Numerous conditions can affect the accuracy of patient recall. Individuals who are older, sicker, less educated and have more negative emotional or psychological states have worse recall of information presented (Jansen et al. 2008; Ong et al. 2000; Liang et al. 2002; Butow et al. 1998). In addition to the many personal attributes that can challenge an individual's recollection, recall also depends on the effective communication of accurate information so it can be conveyed and subsequently recalled. These challenges are great in everyday circumstances but can be even more acute for patients with cancer, a diagnosis fraught with physical and psychological threats. Unlike prior studies, however, we found that recall of information was not affected by individual factors such as age, educational level, emotional status, or type of adjuvant therapy received. In our study, only whether patients felt their needs had been met by the services provided affected recall accuracy.

There are a number of limitations to this study. Because this was a study of women receiving breast cancer care in an urban setting, our findings may not generalize to women receiving care in other settings. We did not assess the quality of the contact that women had with patient assistance programs, although the patient assistance programs were high-quality programs specifically chosen based on previous work evaluating quality of patient assistance programs in New York City (Cohen et al. 2009). Moreover, we did not assess contact with patient assistance programs among the usual care group at the 2 week phone call and are unable to assess their true level of utilization. Thus, it is quite possible that our measure of recall is an underestimate. Still it is striking that of the 79 women who did contact a patient assistance program, only a third of them recalled doing so at 6 months, even after adjusting for age, education and receipt of chemotherapy, which might affect memory (Koppelmans et al. 2012).

Accuracy of breast cancer patients' survey responses about patient assistance program utilization is strongly related to their perception of the usefulness of the services received. Our findings should make researchers and others take pause regarding use of patient report as a reliable source to assess program utilization since it appears that recall was closely related to patients' perceptions of whether the program helped them.

\section{Competing interests}

The authors declare they have no conflict of interest.

\section{Authors' contributions}

$J \mathrm{~L}$ contributed to the data analysis and interpretation and drafted the manuscript. KF contributed to the data analysis and interpretation and writing and editing the manuscript. RF contributed to the study concept and design, data collection and assembly, data analysis and interpretation, and editing of the manuscript. NB contributed to the study concept and design, data collection and assembly, data analysis and interpretation, writing of the manuscript, and editing and approval of the final manuscript. All authors read and approved the final manuscript.

\section{Acknowledgements}

Funding: This work was funded by the National Cancer Institute (5R01CA107051). Dr. Lin is also funded by the American Cancer Society Cancer Control Career Development Grant (CCCDA-10-084-01).

\section{Author details}

'Division of General Internal Medicine, Mount Sinai School of Medicine, One Gustave L. Levy Place, Box 1087, New York, NY 10029, USA. ²Department of Health Evidence and Policy, Mount Sinai School of Medicine, New York, NY, USA.

Received: 19 July 2012 Accepted: 6 September 2012

Published: 3 October 2012

\section{References}

Allicock M, Campbell MK, Valle CG, Barlow JN, Carr C, Meier A, Gizlice Z. (2010) Evaluating the implementation of peer counseling in a church-based dietary intervention for African Americans. Patient education and counseling 81 (1):37-42

Bancej CM, Maxwell CJ, Snider J (2004) Inconsistent self-reported mammography history: findings from the National Population Health Survey longitudinal cohort. BMC Health Serv Res 4(1):32

Bickell NA (2999) Quality of breast cancer Care: perception vs practice. J Clin Oncol, in press

Boudreau DM, Daling JR, Malone KE, Gardner JS, Blough DK, Heckbert SR. (2004) A validation study of patient interview data and pharmacy records for antihypertensive, statin, and antidepressant medication use among older women. Am J Epidemiol 159(3):308-317

Butow P, Brindle E, McConnell D, Boakes R, Tattersall M. (1998) Information booklets about cancer: factors influencing patient satisfaction and utilization. Patient education and counseling 33(2):129-141

Caplan LS, McQueen DV, Qualters JR, Leff M, Garrett C, Calonge N. (2003a) Validity of women's self-reports of cancer screening test utilization in a managed care population. Cancer Epidemiol Biomarkers Prev 12(11 Pt 1):1182-1187

Caplan LS, Mandelson MT, Anderson LA (2003b) Validity of self-reported mammography: examining recall and covariates among older women in a Health Maintenance Organization. Am J Epidemiol 157(3):267-272

Caskie Gl, Willis SL (2004) Congruence of self-reported medications with pharmacy prescription records in low-income older adults. Gerontologist 44(2):176-185

Clegg LX, Potosky AL, Harlan LC, Hankey BF, Hoffman RM, Stanford JL, Hamilton AS. (2001) Comparison of self-reported initial treatment with medical records: 
results from the prostate cancer outcomes study. Am J Epidemiol 154(6):582-587

Cohen A, Mohan KN, Fei K, Geduld AN, Bickell NA. (2009) Are patient assistance programmes able to meet the needs of New York City women with breast cancer? Women's perspectives. European journal of cancer care 18(1):50-56

Craig BM, Quinn GP, Vadaparampil ST. (2009) Sensitivity of self-report mammography use in older women. Am J Prev Med 37(5):441-444

David N, Schlenker P, Prudlo U, Larbig W. (2011) Online counseling via e-mail for breast cancer patients on the German internet: preliminary results of a psychoeducational intervention. Psychosoc Med 8:Doc05

Desai MM, Bruce ML, Desai RA, Druss BG. (2001) Validity of self-reported cancer history: a comparison of health interview data and cancer registry records. Am J Epidemiol 153(3):299-306

Epstein AM, Lee TH, Hamel MB. (2004) Paying physicians for high-quality care. N Engl J Med 350(4):406-410

Ferrante JM, Ohman-Strickland P, Hahn KA, Hudson SV, Shaw EK, Crosson JC, Crabtree BF. (2008) Self-report versus medical records for assessing cancerpreventive services delivery. Cancer Epidemiol Biomarkers Prev 17(11):2987-2994

Fiscella K, Ransom S, Jean-Pierre P, Cella D, Stein K, Bauer JE, Crane-Okada R, Gentry S, Canosa R, Smith T et al (2011) Patient-reported outcome measures suitable to assessment of patient navigation. Cancer 117(15 Suppl):3603-3617

Freund KM, Battaglia TA, Calhoun E, Dudley DJ, Fiscella K, Paskett E, Raich PC, Roetzheim RG. (2008) National Cancer Institute Patient Navigation Research Program: methods, protocol, and measures. Cancer 113(12):3391-3399

Gabrijel S, Grize L, Helfenstein E, Brutsche M, Grossman P, Tamm M, Kiss A. (2008) Receiving the diagnosis of lung cancer: patient recall of information and satisfaction with physician communication. J Clin Oncol 26(2):297-302

Gordon NP, Hiatt RA, Lampert DI. (1993) Concordance of self-reported data and medical record audit for six cancer screening procedures. J Natl Cancer Inst 85(7):566-570

Howard M, Agarwal G, Lytwyn A (2009) Accuracy of self-reports of Pap and mammography screening compared to medical record: a meta-analysis. Cancer Causes Control 20(1):1-13

Jansen J, Butow PN, van Weert JC, van Dulmen S, Devine RJ, Heeren TJ, Bensing $J M$, Tattersall MH (2008) Does age really matter? Recall of information presented to newly referred patients with cancer. J Clin Oncol 26(33):5450-5457

Kessels RP (2003) Patients' memory for medical information. J R Soc Med 96(5):219-222

Koppelmans V, Breteler MM, Boogerd W, Seynaeve C, Gundy C, Schagen SB. (2012) Neuropsychological performance in survivors of breast cancer more than 20 years after adjuvant chemotherapy. J Clin Oncol: official journal of the American Society of Clinical Oncology 30(10):1080-1086

Kravitz R (1998) Patient satisfaction with health care: critical outcome or trivial pursuit? Journal of general internal medicine 13(4):280-282

LaVeist TA, Nickerson KJ, Bowie JV. (2000) Attitudes about racism, medical mistrust, and satisfaction with care among African American and white cardiac patients. Med Care Res Rev 57(Suppl 1):146-161

Liang W, Burnett CB, Rowland JH, Meropol NJ, Eggert L, Hwang YT, Silliman RA, Weeks JC, Mandelblatt JS. (2002) Communication between physicians and older women with localized breast cancer: implications for treatment and patient satisfaction. J Clin Oncol 20(4):1008-1016

Liu Y, Diamant AL, Thind A, Maly RC. (2010) Validity of self-reports of breast cancer treatment in low-income, medically underserved women with breast cancer. Breast cancer research and treatment 119(3):745-751

Lubeck DP, Hubert HB. (2005) Self-report was a viable method for obtaining health care utilization data in community-dwelling seniors. J Clin Epidemiol 58(3):286-290

Mandelson MT, LaCroix AZ, Anderson LA, Nadel MR, Lee NC. (1999) Comparison of self-reported fecal occult blood testing with automated laboratory records among older women in a health maintenance organization. Am J Epidemiol 150(6):617-621

Maunsell E, Drolet M, Ouhoummane N, Robert J. (2005) Breast cancer survivors accurately reported key treatment and prognostic characteristics. J Clin Epidemiol 58(4):364-369

Nissen MJ. Tsai ML. (2011) Blaes AH. Breast and colorectal cancer survivors' knowledge about their diagnosis and treatment. J Cancer Surviv, Swenson KK
Oberst K, Bradley CJ, Schenk M. (2009) Breast and prostate cancer patient's reliability of treatment reporting. J Registry Manag 36(1):12-15

Ong LM, Visser MR, Lammes FB, van Der Velden J, Kuenen BC, de Haes JC. (2000) Effect of providing cancer patients with the audiotaped initial consultation on satisfaction, recall, and quality of life: a randomized, double-blind study. J Clin Oncol 18(16):3052-3060

Paganini-Hill A, Clark $\sqcup$ (2007) Comparison of patient recall of hormone therapy with physician records. Menopause 14(2):230-234

Paskett ED, Tatum CM, Mack DW, Hoen H, Case LD, Velez R. (1996) Validation of self-reported breast and cervical cancer screening tests among low-income minority women. Cancer Epidemiol Biomarkers Prev 5(9):721-726

Penfold RB, Kullgren JT, Miroshnik I, Galbraith AA, Hinrichsen VL, Lieu TA. (2011) Reliability of a patient survey assessing cost-related changes in health care use among high deductible health plan enrollees. BMC Health Serv Res 11:133

Phillips KA, Milne RL, Buys S, Friedlander ML, Ward JH, McCredie MR, Giles GG, Hopper JL. (2005) Agreement between self-reported breast cancer treatment and medical records in a population-based Breast Cancer Family Registry. J Clin Oncol 23(21):4679-4686

Pickney CS, Arnason JA. (2005) Correlation between patient recall of bone densitometry results and subsequent treatment adherence. Osteoporos Int 16(9):1156-1160

Posma ER, van Weert JC, Jansen J, Bensing JM (2009) Older cancer patients' information and support needs surrounding treatment: An evaluation through the eyes of patients, relatives and professionals. BMC Nurs 8:1

Schootman M, Jeffe DB, West MM, Aft R. (2005) Self-report by elderly breast cancer patients was an acceptable alternative to surveillance, epidemiology, and end results (SEER) abstract data. J Clin Epidemiol 58(12):1316-1319

Sohler NL, Coleman SM, Cabral H, Naar-King S, Tobias C, Cunningham CO. (2009) Does self-report data on HIV primary care utilization agree with medical record data for socially marginalized populations in the United States? AIDS Patient Care STDS 23(10):837-843

Strogatz DS, Croft JB, James SA, Keenan NL, Browning SR, Garrett JM, Curtis AB. (1997) Social support, stress, and blood pressure in black adults. Epidemiology Cambridge, Mass 8(5):482-487

Takach M. (2011) Reinventing Medicaid: state innovations to qualify and pay for patient-centered medical homes show promising results. Health affairs (Project Hope) 30(7):1325-1334

Turnbull JE, Luther KM. (1996) Patient satisfaction report paves way to improved care. QRC Advis 13(1):1-7

van Campen C, Sixma H, Friele RD, Kerssens JJ, Peters L. (1995) Quality of care and patient satisfaction: a review of measuring instruments. Med Care Res Rev 52(1):109-133

Watson PW, McKinstry B. (2009) A systematic review of interventions to improve recall of medical advice in healthcare consultations. J R Soc Med 102(6):235-243

Zapka JG, Bigelow C, Hurley T, Ford LD, Egelhofer J, Cloud WM, Sachsse E. (1996) Mammography use among sociodemographically diverse women: the accuracy of self-report. Am J Public Health 86(7):1016-1021

doi:10.1186/2193-1801-1-24

Cite this article as: Lin et al:: Breast cancer patients' recall of receiving patient assistance services. SpringerPlus 2012 1:24.

\section{Submit your manuscript to a SpringerOpen ${ }^{\odot}$ journal and benefit from:}

- Convenient online submission

$\checkmark$ Rigorous peer review

- Immediate publication on acceptance

- Open access: articles freely available online

- High visibility within the field

- Retaining the copyright to your article

Submit your next manuscript at $\gg$ springeropen.com 